\title{
Impressions from Vienna at the CED-IADR / NOF Oral Health Research Congress
}

The biennial Continental European Division (CED) and Scandinavian division (Nordisk Odontologisk Förening, NOF) meeting of the International Association of Dental Research (IADR) was organized in Vienna at the end of September this year.

The congress included an intensive two-and-half day program of oral presentations, posters, keynote \& symposia lectures. More than 800 participants, among whom more than $25 \%$ were students, from more than 50 countries attended the congress, which proved to be one of the most important European events in the field of dental research. The most recent research findings, focusing on the latest innovations, developments and trends in the various sub-disciplines of dentistry were discussed at this event. A lot of attention, while organizing each CED-IADR congress, is indeed paid to creating the possibilities of networking so as to imagine, invent and inspire each other. The modern congress venue 'Messe Wien' and the size of the congress had the advantage of facilitating easy interactions with colleagues, friends \& peers in the broad field of dental research.

The main outcomes of the meeting confirmed the Association's main goal of encouraging high-quality Oral Health Research in Europe, especially among young people. Indeed, several innovative features were introduced in the meeting program as of this year, such as a greatly reduced registration fee for students and young researchers, a newly installed 'My First Research' poster award competition and a 'Young CED-IADR' symposium organized and delivered by young researchers. The latter one meant that young researchers under 35 years of age with a very promising career fully presented, organized and moderated the event. The purpose of this activity was to encourage young people to have a better understanding of a specific topic of dental research, that of the interactions between dental materials and oral biofilms, and to generate a productive discussion. The symposium was very well received, and it is hoped that this activity will be implemented in the program of the future meetings. The meeting also included a special full-day scientific program to celebrate the '100-year anniversary' of the NOF Division. A special clinical satellite symposium on selected new trends in restorative dentistry, as well as a session with clinical case poster presentations were also organized, their specific aim being to narrow the existing gap between dental researchers and clinicians.
The CED-IADR/NOF Oral Health Research Congress allowed further networking and getting in touch with each other during the two social events: the opening ceremony in the Vienna city hall and the 'Congress Get-together' which was held inside the University Dental Clinic of Vienna.

The next meetings of the Association are scheduled to take place in London, UK, July 25-28, 2018, as a General Session together with all the other divisions, and in Madrid, Spain, September 19-21, 2019 as CED-IADR.

For any information, please refer to the website of the organization: https://ced-iadr.eu/ and the secretariat email: ced.iadr@uzleuven.be. 